\section{IJDMT}

(C) I A E M E

\title{
PREDICTION OF LIMITING DRAW RATIO (LDR) BY USING FINITE ELEMENT METHOD (FEM) BASED SOFTWARE SIMULATIONS
}

\author{
Namraj Garhewal ${ }^{1}$, Pravin Kumar Singh ${ }^{2}$ \\ ${ }^{1} \mathrm{M}$. Tech Scholar, Department of mechanical engineering, University institute of technology, \\ Barkatullah University, Bhopal, India. \\ ${ }^{2}$ Assistant professor, Department of mechanical engineering, University institute of \\ technology, Barkatullah University, Bhopal, India.
}

\begin{abstract}
Deep drawing process of sheet metal is mostly used for cup shape forming. For cup shape forming a limiting value of blank diameter, for which value we can successfully draw a cup. If the punch diameter, efficiency factor and all the process parameters are fixed, and we increase that value of blank diameter, then the limit value of failure can be obtained. The ratio of maximum blank diameter which is successfully drawn to the punch diameter is called LDR (Limiting Drawing Ratio). Analytically we can find out the value of LDR. We can find out the value of LDR also from Experiments. But there is a big difference between the analytical value and experimental value. The value of LDR is also find out by the software simulation of deep drawing process and this value is very close to the experimental value of LDR. So with the help of simulation we can predict the value of LDR, which can reduce the experimental set up cost. We are using RADIOSS software for FEM simulation of deep drawing process.

The work presented in this paper focuses on the concept of deep drawing. All the materials considered are elastic. The material used is SAE_J2340_CR_210A_Dent_Resist. The software used for the simulation and analysis is RADIOSS software.

For the analysis, constant process parameters like punch speed; blank holding force, punch travel and friction co-efficient have been considered. On these parameters different blank diameters, within $0.5 \mathrm{~mm}$ interval, have been considered in order to find out various safe, marginal and failure conditions for different materials respectively.

In this simulation, the displacement of material under deep drawing of cup shape, plastic strain on different sections of the cup and \% age thinning have been analyzed. Safe value, marginal value and the failure limit of various materials with different diameters taking into consideration have been observed. It has also been observed that the zone of minimum displacement (dark blue color of the displacement diagram) varies from higher to lower
\end{abstract}


International Journal of Design and Manufacturing Technology (IJDMT), ISSN 0976 - 6995(Print), ISSN 0976 - 7002(Online) Volume 4, Issue 3, September - December (2013), ( I IAEME

progressively safe condition towards failure condition. And this dark blue zone goes on decreasing progressively.

With the help of this paper, it has been shown that the value of LDR by simulation is very close to value obtained of LDR by experimental value (published data). With the value of LDR, the failure condition of different materials in deep drawing process has been predicted.

Keywords: Deep drawing, FEM simulation, LDR, Forming Limit Diagram, RADIOSS.

\section{INTRODUCTION}

The ability to produce a variety of shape from sheet of metal at high rate of production is one of the outstanding qualities of the sheet metal working processes. The importance of sheet metal working process in modern technology is due to the ease with which metal may be formed into useful shapes by plastic stage deformation process in which the volume and mass of metal are conserved and metal is only displaced from one position to another. Deep drawing is one of the widely used sheet metal working process to produce cup shaped component at very high rate. Sheet metal forming process serves as a basic test for the sheet metal formability. In deep drawing process a sheet of metal is used to form cylindrical component by pressing the central portion of the sheet into die opening to form the metal into desired shape. The efficiency of deep drawing process depends upon many parameters and the choice of these parameters is very important to achieve the high drawability. The deformation of sheet metal in deep drawing can be quantitatively estimated by dwaw ratio (DR), which is defined as the ratio of initial blank diameter to the diameter of the cup drawn from the blank (approximately equal to punch diameter). For a given material there is a limiting draw ratio (LDR), representing the largest blank that can be drawn through the die successfully. The drawability of the metal depends on two factors.

1. The ability of material in the flange region to flow easily in the plane of sheet under shear.

2. The ability of side wall material to resist deformation in the thickness direction.

The mechanical properties which are considered to the important in sheet formability are average plastic strain ratio $(\bar{r})$ and the strain hardening component $(n)$. The strength of final part as measured by yield strength must also be considered. Take both the above mentioned factors into account it is desirable in the drawing operation to minimize material flow in the plane of the sheet and to maximize resistant to material flow in direction perpendicular to the plane of the sheet.

The flow strength of sheet metal in the thickness direction is difficult to measure, but the plastic-strain ratio $r$ compares strengths in the plane and thickness directions by determining true strains in these directions in a tension test. For a given metal strained in a particular direction, $r$ is a constant expressed as:

Where

$$
r=\frac{\epsilon_{w}}{\epsilon_{t}}
$$

$\epsilon_{w}=$ True strain in width direction.

$\epsilon_{t}=$ True strain in thickness direction.

E I Sebaie and mellor conducted various experiments which sheets having $n$-values varying between 0.2 and 0.5 and found out that the $n$-value has little effect on LDR while the $\bar{r}$ value plays a dominant role and that for materials having $\bar{r}$ value less than unity, the LDR 
International Journal of Design and Manufacturing Technology (IJDMT), ISSN 0976 - 6995(Print), ISSN 0976 - 7002(Online) Volume 4, Issue 3, September - December (2013), ( I IAEME

should be approximately constant for all values of $n$ or variation is very small. It was also observed that in many cases higher LDR would be achieved if the instability site could be transferred from the cup wall to the flange. Several theoretical analyses have been proposed for predicting the LDR. There has been considerable effort in recent years towards the development and use of FEM (finite element method) models to solve the deep drawing problems in a better way.

\section{METHODOLOGY}

Analytical LDR

Initially, Whiteley proposed the following equation to predict LDR:

$$
L D R=e^{\eta \sqrt{\frac{1+\bar{R}}{2}}}
$$

Where

$\eta=$ Efficiency factor of deep drawing process

$\bar{R}=$ Normal anisotropy of sheet

\section{Preparation of CAD model}

According to the published parameters we are preparing a CAD model of the arrangement of tool for the deep drawing simulation. We are using CATIA V5 R20 as a CAD tool for modeling of our arrangement.

\section{Process simulation of deep drawing}

For process simulation we used Altair RADIOSS is a next-generation finite element solver for linear and non-linear simulations. It can be used to simulate structures, fluids, fluidstructure interaction, sheet metal stamping, and mechanical systems. This robust, multidisciplinary solution allows manufacturers to maximize durability, noise and vibration performance, crashworthiness, safety, and manufacturability of designs in order to bring innovative products to market faster.

RADIOSS has been an industry staple for high-speed impact simulation for over 20 years. Automotive and aerospace companies value the contribution it makes in understanding and predicting design behavior in complex environments. In recent years thru the addition of implicit finite element solver capabilities RADIOSS has become a viable option also for standard analyses and linear dynamics.

The tight integration with HyperWorks environment makes RADIOSS a powerful design tool. Aside from modeling and visualization, RADIOSS models are ready for optimization. Transition to the optimization solver OptiStruct and Hyper Study is easy.

\section{Preprocessing}

FEA codes with an explicit numerical scheme are today's state-of-the-art tools for metal forming, automotive crash, drop test and stamping simulations. While technology and processes progress, an optimization study or a full-vehicle robustness analysis needs at least ten different runs, so it's important to reduce their elapse time significantly.

The method dramatically reduces the elapsed time, without modifying neither the mass of the model nor the rigid body translations, therefore providing very accurate results. Examples will we provided to illustrate how the method can be applied on large-scale FEA models. We are using HYPERMESH software for the meshing of geometry. 
International Journal of Design and Manufacturing Technology (IJDMT), ISSN 0976 - 6995(Print), ISSN 0976 - 7002(Online) Volume 4, Issue 3, September - December (2013), () IAEME

We have done various simulations with different diameter in the interval of $0.5 \mathrm{~mm}$ (90 mm, $90.5 \mathrm{~mm}, 91 \mathrm{~mm}, 91.5 \mathrm{~mm}, 92 \mathrm{~mm}, 92.5 \mathrm{~mm}, 93 \mathrm{~mm}$ like this) and found the results.

\section{Material property}

\begin{tabular}{|c|c|c|c|c|c|}
\hline Material & $\begin{array}{c}\text { YS } \\
\mathbf{N} / \mathbf{m m}^{2}\end{array}$ & $\begin{array}{c}\text { UTS } \\
\mathbf{N} / \mathbf{m m}^{2}\end{array}$ & $\begin{array}{c}\text { Anisotropy } \\
\bar{R}\end{array}$ & $\begin{array}{c}\text { Strength } \\
\text { coefficient } \\
\mathbf{K}\end{array}$ & $\begin{array}{c}\text { Strain } \\
\text { hardening } \\
\text { exponent } \\
\mathbf{n}\end{array}$ \\
\hline SAE_J2340_CR_210A_Dent_Resist & 210 & 584 & 1.6 & 630 & 0.186 \\
\hline
\end{tabular}

\section{Process parameters}

\begin{tabular}{|l|l|}
\hline Process parameter & Value \\
\hline Blank holding Force & $20 \mathrm{KN}$ \\
\hline Punch travel & $45 \mathrm{~mm}$ \\
\hline Punch speed & $200 \mathrm{~mm} / \mathrm{sec}$ \\
\hline Co-efficient of friction & 0.125 \\
\hline
\end{tabular}

\section{RESULTS \& DISCUSSION}

\section{Blank diameter $91 \mathrm{~mm}$}

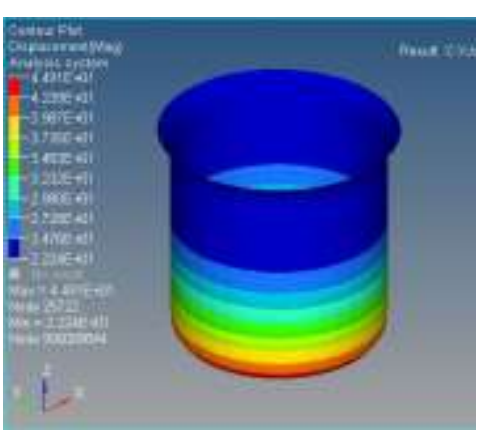

Fig1. Displacement contours

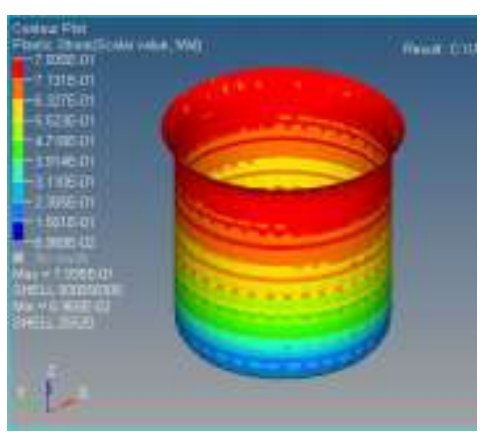

Fig2. Plastic strain contours

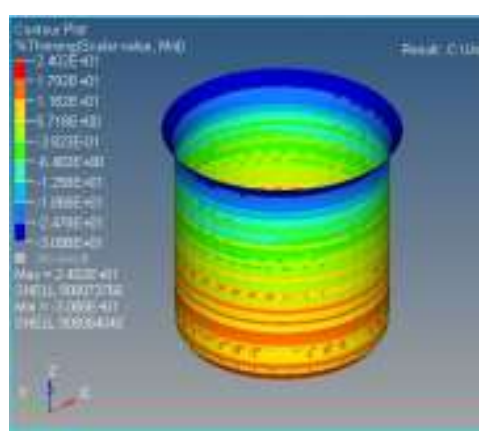

Fig3. $\%$ age thinning contours

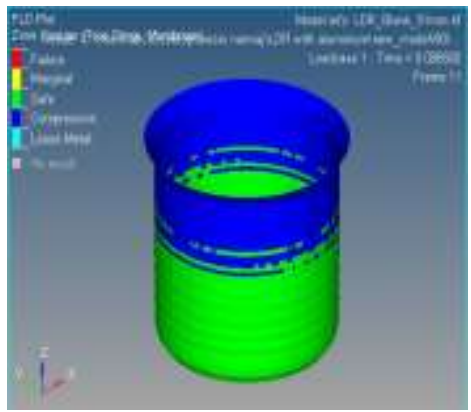

Fig4. FLD plot contours

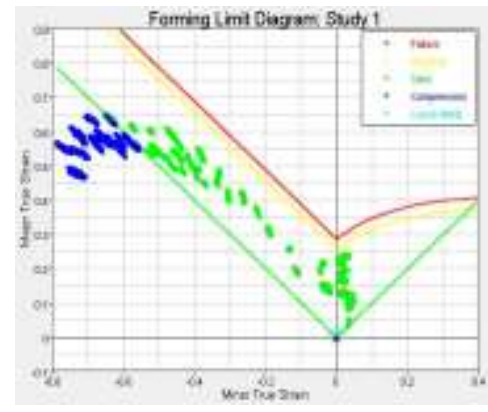

Fig5. Forming limit diagram 
International Journal of Design and Manufacturing Technology (IJDMT), ISSN 0976 - 6995(Print), ISSN 0976 - 7002(Online) Volume 4, Issue 3, September - December (2013), (C IAEME

\section{Blank diameter $91.5 \mathrm{~mm}$}

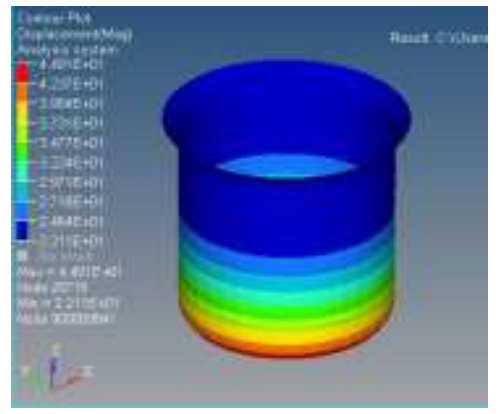

Fig6. Displacement contours

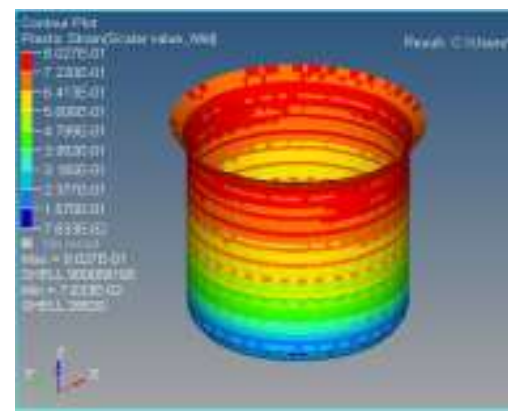

Fig7. Plastic strain contours

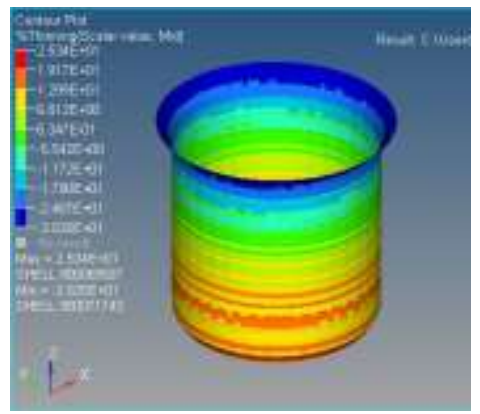

Fig8. \% age thinning contours

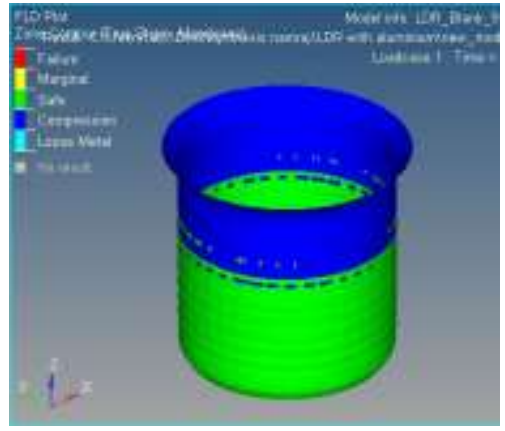

Fig9. FLD plot contours

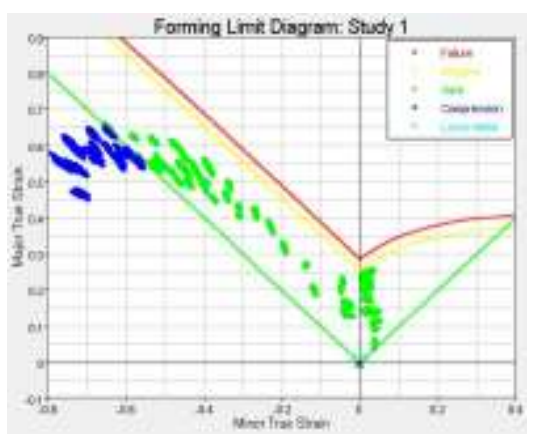

Fig10. Forming limit diagram3

\section{Blank diameter $92 \mathrm{~mm}$}

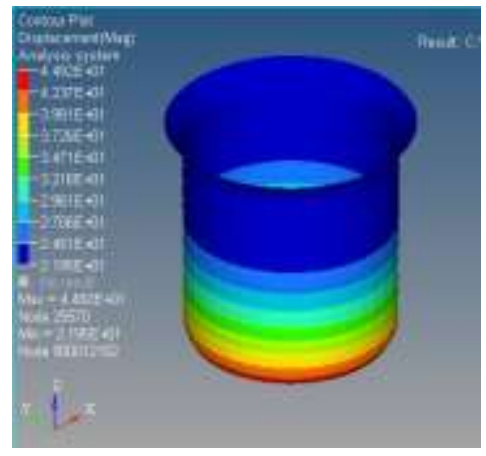

Fig11. Displacement contours

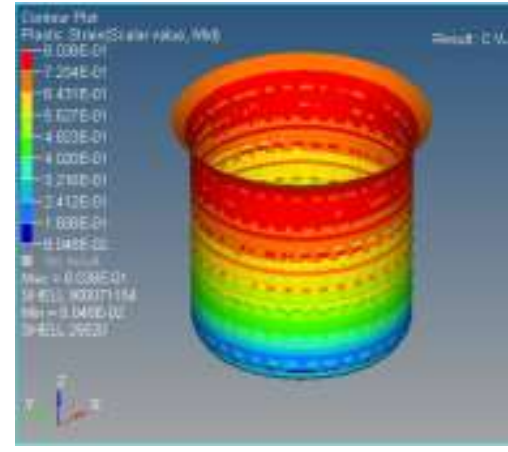

Fig12. Plastic strain contours

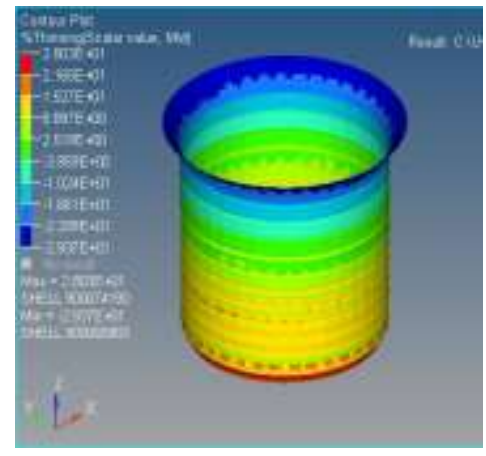

Fig13. $\%$ age thinning contours

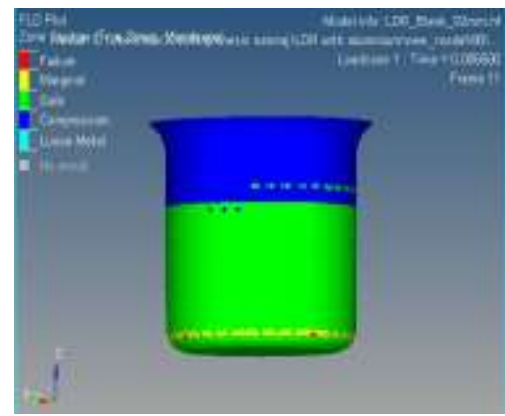

Fig14. FLD plot contours

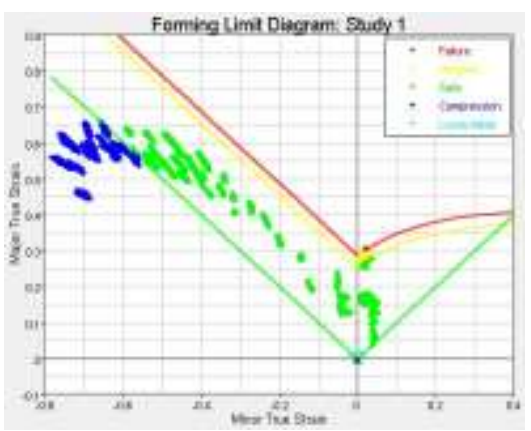

Fig15. Forming limit diagram 
International Journal of Design and Manufacturing Technology (IJDMT), ISSN 0976 - 6995(Print), ISSN 0976 - 7002(Online) Volume 4, Issue 3, September - December (2013), ( I IAEME

\section{Result table}

\begin{tabular}{|c|l|c|c|c|c|c|}
\hline $\begin{array}{c}\text { Case } \\
\text { No. }\end{array}$ & \multicolumn{1}{|c|}{ Material } & $\begin{array}{c}\text { Blank } \\
\text { diameter } \\
(\mathbf{m m})\end{array}$ & $\begin{array}{c}\text { Condition } \\
\text { of } \\
\text { material }\end{array}$ & $\begin{array}{c}\text { Analytical } \\
\text { LDR }\end{array}$ & $\begin{array}{c}\text { LDR } \\
\text { by } \\
\text { simulation }\end{array}$ & $\begin{array}{c}\text { \%age } \\
\text { Deviation }\end{array}$ \\
\hline 1. & $\begin{array}{l}\text { SAE_J2340_CR_210A_Dent_ } \\
\text { Resist }\end{array}$ & 91 & Safe & ---- & ---- & ---- \\
\hline 2. & $\begin{array}{l}\text { SAE_J2340_CR_210A_Dent_ } \\
\text { Resist }\end{array}$ & 91.5 & Marginal & 2.79 & 2.346 & 16 \\
\hline 3. & $\begin{array}{l}\text { SAE_J2340_CR_210A_Dent_ } \\
\text { Resist }\end{array}$ & 92 & Fail & ----- & ---- & ---- \\
\hline
\end{tabular}

\section{Discussion}

During the analysis of these results we had seen that material SAE_J2340_CR_210A_Dent_Rasist is successfully drawn on the $91.5 \mathrm{~mm}$ diameter of blank. If we increase its diameter more, it will we fail. That means, this material will fail on $92 \mathrm{~mm}$ blank diameter, if the process parameters are same.

In this simulation we have also analyzed the displacement of material under deep drawing of cup shape, plastic strain on different sections of the cup and \% age thinning. We have observed safe value, marginal value and the failure limit of various materials with different diameters taking into consideration. It is also observed that the zone of minimum displacement (dark blue in displacement diagram of all cases) varies from higher to lower progressively safe condition towards failure condition. And this dark blue zone goes on decreasing progressively.

\section{CONCLUSION}

We have taken materials into consideration namely SAE_J2340_CR_210A_Dent_Resist, for simulation under constant process parameters. Thereby, analyzing conditions like displacement of material under deep drawing, plastic strain, $\%$ age thinning and forming limit diagram (FLD) of these materials.

We considered the above material under different blank diameters (with $0.5 \mathrm{~mm}$ interval in between). We observed safe, marginal and failure conditions for each material. This shows the limiting value of diameters for predicting the value of LDR. The observation comes from the comparison between deviation of results from analytical values to the simulation values are almost constant around 16\%. Which is comparatively good correlation.

Thus, LDR is indirectly becomes a factor for determining the extent of deep drawing ability of different materials.

\section{REFERENCES}

\section{Journal Papers}

[1] D. K. Leu, Prediction of limiting drawing ration and maximum drawing load in the cup drawing, International Journal of Mechanical Science. 37 (2) (1997) 201-213.

[2] S. P. Keeler, Understanding sheet metal formability, National Steel Corporation, USA 3 (1968) 357-265. 
[3] M. G. EI-Sebaie, mellor, Plastic instability conditions in the deep drawing of circular blank of sheet metal, International Journal of Mechanical Science. 14 (1972) 535-556.

[4] Naval Kishor, D. Ravi Kumar, optimization of initial blank shape to minimize earing in deep drawing using finite element method, journal of material processing technology 130-131 (2002) 20-30.

[5] Kuang-Hua Chang, "Sheet Metal Forming Simulation" Product Manufacturing and Cost Estimating Using Cad/Cae, 2013, Pages 133-190.

[6] Dr.R.Uday Kumar, "Mathematical Modeling and Analysis of Hoop Stresses in Hydroforming Deep Drawing Process", International Journal of Advanced Research in Engineering \& Technology (IJARET), Volume 3, Issue 2, 2012, pp. 43 - 51, ISSN Print: 0976-6480, ISSN Online: 0976-6499.

[7] Min HE, Fuguo LI, Zhigang WANG, "Forming Limit Stress Diagram Prediction of Aluminum Alloy 5052 Based on GTN Model Parameters Determined by In Situ Tensile Test", Chinese Journal of Aeronautics, Volume 24, Issue 3, June 2011, Pages 378386.

[8] Dr.R.Uday Kumar and Dr.P.Ravinder Reddy, "Influence of Viscosity on Fluid Pressure in Hydroforming Deep Drawing Process", International Journal of Mechanical Engineering \& Technology (IJMET), Volume 3, Issue 2, 2012, - 609, ISSN Print: 0976 - 6340, ISSN Online: 0976 - 6359.

pp. 604

[9] Q. Situ, M.K. Jain, D.R. Metzger, "Determination of forming limit diagrams of sheet materials with a hybrid experimental-numerical approach " International Journal of Mechanical Sciences, Volume 53, Issue 9, September 2011, Pages 707-719.

[10] Dr.R.Uday Kumar, "Mathematical Modeling and Evaluation of Radial Stresses in Hydroforming Deep Drawing Process", International Journal of Mechanical Engineering \& Technology (IJMET), Volume 3, Issue 2, 2012, pp. 693 - 701, ISSN Print: 0976 - 6340, ISSN Online: 0976 - 6359.

[11] Wolfram Volk, Hartmut Hoffmann, Joungsik Suh, Jaekun Kim, "Failure prediction for nonlinear strain paths in sheet metal forming" CIRP Annals - Manufacturing Technology, Volume 61, Issue 1, 2012, Pages 259-262.

\section{Books}

[1] ASM Metals Hand Book Volume 14 - Forming and Forging.

[2] E. Dieter George, mechanical Metallurgy, vol.4, McGraw Hill Book Company, London, 1981. 